\title{
Impact of hyperkalemia and worsening renal function on the use of renin angiotensin aldosterone system inhibitors in chronic heart failure with reduced ejection fraction
}

Bertram Pitt ${ }^{1}, \mathrm{MD}$, Patrick Rossignol ${ }^{2}, \mathrm{MD}, \mathrm{PhD}$

1. University of Michigan School of Medicine, Ann Arbor, Michigan, USA.

2. Inserm, Centre d’Investigations Cliniques- Plurithématique 14-33, Inserm U1116, CHRU Nancy, Université de Lorraine, and F-CRIN INI-CRCT (Cardiovascular and Renal Clinical Trialists), Nancy, France

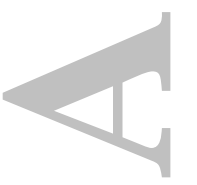

Corresponding author: Pr Patrick Rossignol

Centre d’Investigations Cliniques Plurithématique-INSERM CHRU de Nancy

Institut lorrain du Cœur et des Vaisseaux Louis Mathieu

4 rue du Morvan

54500 Vandoeuvre Lès Nancy

France

Tel: +33 383157320

Fax: +33383157324

p.rossignol@chru-nancy.fr

Word Count: 1595/1600

This is the author manuscript accepted for publication and has undergone full peer review but has not been through the copyediting, typesetting, pagination and proofreading process, which may lead to differences between this version and the Version record. Please cite this article as doi:10.1002/ cpt.746. 
Introduction Patients with heart failure (HF) and reduced ejection fraction (HFREF) are at increased risk of death and hospitalizations for HF. Numerous registries have reported a large and persistent gap between real-life practice in the use of life-saving evidence-based therapies (such as renin angiotensin system inhibitors, beta blockers, mineralocorticoid receptor antagonists (MRA) and recommended practices in international guidelines. The fear of inducing hyperkalemia and or worsening renal function are the main triggers of this underuse.

\section{The problem: epidemiology and lack of use of effective therapeutics}

The MRA spironolactone and eplerenone have been shown to reduce cardiovascular death and hospitalizations for heart failure as well as total mortality and total hospitalizations in patients with chronic heart failure and HFREF. On this basis they have received a class 1 indication in major European and US guidelines ${ }^{1}$. In contrast to other class 1 recommendations for patients with chronic HFREF such as beta adrenergic receptor antagonists and angiotensin converting enzyme inhibitors (ACE-I) or angiotensin receptor blockers (ARB) the use of MRA remains suboptimal both in Europe and the US ${ }^{1}$. In large part, this under use of MRA in guideline eligible patients with chronic HFREF appears to be due to a fear of inducing serious hyperkalemia and or worsening renal function . Although spironolactone was associated with a 30\% reduction in cardiovascular mortality as well as a significant reduction in hospitalizations for heart failure in patients with severe chronic HFREF (Randomized Aldactone Evaluation Study (RALES)) a report by Juurlink et al $^{2}$ in the New England Journal of Medicine from Canada soon after the publication of the results of the RALES study pointed out that the use of spironolactone in patients with chronic HFREF was associated with an increase in hospitalization for hyperkalemia. A critical review of 
the study shows however that many patients in this study used a dose higher than the dose of spironolactone recommended in the RALES study (12.5-50 mg/day) ; had worse renal function than patients included in the RALES study ; and most importantly in contrast to patients in RALES many patients from Canada had a baseline serum potassium ( $\mathrm{K}+$ ) $>5.0 \mathrm{mmol} / \mathrm{l}$ and or did not undergo serial monitoring of $\mathrm{K}+$ and renal function. Furthermore, Juurlink's findings were not replicated in a longitudinal analysis of the UK National Health Service in Scotland. In this study, an increase in mild hyperkalemia was reported after the publication of RALES, but it did not translate into increased hospitalizations or death due to hyperkalemia. The authors attributed the finding to more rigorous monitoring practices ${ }^{3}$. Given the risk of sudden cardiac death associated with the development of hyperkalemia $(\mathrm{K}+>5.0 \mathrm{mmol} / \mathrm{l})^{4}$ as well as the increased costs associated with the need for hospitalization of patients with hyperkalemia it is understandable that clinicians trained to " do no harm" have tended to avoid initiating MRA in guideline eligible patients with chronic HFREF. However while the fear of inducing hyperkalemia is reasonable in patients at increased risk for its development such as those with an estimated glomerular filtration rate (eGFR) $<45 \mathrm{ml} / \mathrm{min} / 1.73 \mathrm{~m}^{2}$ and or a $\mathrm{K}+>4.8 \mathrm{mmol} / \mathrm{l}$, MRA are also avoided in patients with chronic HFREF at a relatively low risk for developing serious hyperkalemia ( $\mathrm{K}+\geq 6.0$ $\mathrm{mmol} / \mathrm{l}$ ), thereby denying these patients proven life and cost saving therapy. In a consecutive series of 500 patients hospitalized with a diagnosis of acute decompensated HF only $21 \%$ of eligible patients for a MRA on admission received them. Of interest was the finding that preadmission and newly started MRA were discontinued in 36\% of patients during the period of hospitalization, with worsening renal function being the most common identifiable reason. After a medium follow-up of 57 days, an additional $6 \%$ of patients discontinued their MRA ${ }^{5}$. 
Management of patients when hyperkalemia and or worsening renal function interferes with successful use of MRA added to a background of renin angiotensin system blockade.

Recent data have however cast some doubt as to the risks associated with an increase in $\mathrm{K}+$ to > 5.0-5.5 $\mathrm{mmol} / \mathrm{l}$ as well as the risks associated with worsening renal function. While the risk of serious hyperkalemia $(\mathrm{K}+\geq 6.0 \mathrm{mmol} / \mathrm{l})$ is well documented recent data from the Eplerenone in Mild Patients Hospitalization and Survival Study in Heart Failure (EMPHASIS-HF have suggested that the development of mild-moderate hyperkalemia ( $>5.0-5.5 \mathrm{mmol} / \mathrm{l}$ may not be significantly associated with an increased risk of death with a MRA ${ }^{6}$ and that the development of hypokalemia $(\mathrm{K}+<4.0-3.5 \mathrm{mmol} / \mathrm{l})$ may be a far greater risk for death in patients with chronic $\mathrm{HFREF}^{7}$. Importantly in this trial, as per protocol , the patients serum potassium was monitored after 1 week, 1 month, and every 4 months thereafter. Patients with an elevation of serum potassium $\geq 5.5 \mathrm{mmol} / \mathrm{l}$ could decrease study drug or discontinue it in case of hyperkalemia $\geq 6$ mmol/l. The study drug could however be reintroduced if the serum potassium measured within 72 hours, was $<5.0 \mathrm{mmol} / \mathrm{l}$. Serum creatinine was monitored at baseline, month 5 , then every 8 months. If there was an unplanned interruption in the administration of study drug/eplerenone for any period of time, the subject may resume study drug/eplerenone as directed by the investigator. The dosage resumed was at the discretion of the investigator (not to exceed $50 \mathrm{mg}$ once daily for subjects with an eGFR $\geq 50 \mathrm{ml} / \mathrm{min} / 1.73 \mathrm{~m} 2$ and $25 \mathrm{mg}$ once daily with an eGFR between 30-49 $\mathrm{ml} / \mathrm{min} / 1.73 \mathrm{~m}^{2}$ ). The dynamic management of eplerenone ${ }^{6}$ may have contributed to maintenance of study drug throughout the trial as well as to its efficacy and safety. Such an algorithm may provide guidance for the daily management of MRA in clinical practice. Of note, the European Society of Cardiology guidelines for heart failure management includes tables with practical guidance on the use of ACEi/ARB or MRA in patients with HFREF (web tables 7.4 and 7.6) ${ }^{8}$. 
While there is evidence that mild -moderate hyperkalemia can be associated with an increased risk of death, the risk associated with any given level of $\mathrm{K}+$ depends upon the rate of change in $\mathrm{K}+$, intracellular potassium and magnesium levels, serum calcium + level, and $\mathrm{pH}$. The approach to and the treatment of patients with chronic hyperkalemia is undergoing change. Until recently patients with chronic hyperkalemia have been recommend to be on a low potassium diet; to eliminate potassium supplements and drugs that compromise renal function such as non-steroidal anti-inflammatory drugs ; to initiate treatment with a non-potassium sparring diuretic if indicated or if already on a diuretic to increase the dose ; as well as to reduce the dose or discontinue RAASI, especially MRA. However, reducing the dose of the RAAS-I or discontinuing it could place the HFREF patient at increased risk for death. In this situation one might consider the use of a potassium lowering agent while continuing a RAAS-I ${ }^{9}$. Interestingly, the recent availability in the US of the well tolerated and effective potassium lowering agent patiromer which exchanges potassium for calcium allows a reduction of $\mathrm{K}+$ to normokalemic values and may open new therapeutic avenues for hyperkalemic HFREF patients on optimal RAASI regimen ${ }^{9}$.

A recently published metaanalysis of randomized placebo controlled trials of renin angiotensin aldosterone system inhibitors (RAAS)-I) in chronic HF shows that in HFREF, worsening renal function induced by RAAS-I therapy was associated with a less increased relative risk of mortality (Relative Risk (RR) 1.19(1.08-1.31), $\mathrm{p}<0.001$ ), compared with worsening renal function induced by placebo (RR 1.48(1.35-1.62), $\mathrm{p}<0.001)$ (p for interaction 0.005$)^{10}$. The reason for an increase in serum creatinine after initiation of a RAAS-I, especially a MRA, is well understood and is associated with a decrease in vascular tone. There is no evidence that this decrease in renal vascular tone is detrimental and associated with adverse renal structural changes since RAAS-I withdrawal is associated with a return in serum creatinine toward normal. On the contrary evidence suggests 
that RAAS-I, including MRA, have a beneficial effect on renal function and structure. They reduce mesangial and glomerular fibrosis, apoptosis, podocyte loss, and have been shown to have a beneficial effect on cardiovascular and renal outcomes, at least for ACE-I and ARB. Thus, the accumulating evidence would suggest that patients with chronic HFREF who are initiated on a RAAS-I be allowed to continue therapy if they develop worsening renal function (i.e. an increase in serum creatinine $>30 \%$ ). However, if the worsening renal function is associated with serious hyperkalemia $(\mathrm{K}+>6.0 \mathrm{mmol} / \mathrm{l})$ and or new ECG changes suggestive of hyperkalemia; or symptoms associated with the development of renal failure that the RAAS-I be temporarily discontinued and appropriate therapy for hyperkalemia (i.e. a potassium binder), if indicated, be initiated. This may be followed by a re-initiation of RAAS-I after down-titration. This strategy would allow a greater percentage of patients with chronic HFREF to remain on RAAS-I, especially MRA thereby potentially preventing cardiovascular death, hospitalizations for heart failure, and increased health care costs. Further prospective adequately powered randomized clinical trials as well as further analysis of "real life" observational databases or registries will be essential to inform clinical guidelines and practice. In the interim clinicians will need to weigh the risks and benefits of discontinuing RAAS-I, especially MRA, in patients with chronic HFREF who develop mild-moderate hyperkalemia and or worsening renal function on an individual basis. While it may be easier to withdraw a RAAS-I than to continue it in these circumstances the accumulating evidence suggests that in many instances the decision to continue the use of a RAAS-I will in the long run results in a favorable effect on renal structure, function and cardiovascular outcomes.

\section{Disclosures}

Pitt: Personal fees (consulting) from Bayer, KBP Pharmaceuticals, AstraZeneca, Boehringer Ingelheim, Merck, Takeda, Relypsa, Sanofi, sc Pharmaceuticals , Sarfez pharmaceuticals, Tricida; 
stock options from KBP Pharmaceuticals, sc Pharmaceuticals, Sarfez pharmaceuticals, Relypsa and Tricida; patent pending for site specific delivery of eplerenone to the myocardium

Rossignol: Personal fees (consulting) from Bayer, Novartis, Relypsa, AstraZeneca, Stealth Peptides, Fresenius, Vifor Fresenius Medical Care Renal Pharma, and CTMA; lecture fees from CVRx; cofounder CardioRenal

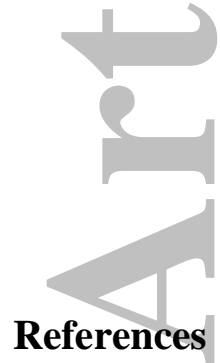

1. Pitt B and Rossignol P. The safety of mineralocorticoid receptor antagonists (MRAs) in patients with heart failure. Expert Opin Drug Saf. 2016;15:659-65.

2. Juurlink DN, Mamdani MM, Lee DS, Kopp A, Austin PC, Laupacis A and Redelmeier DA. Rates of hyperkalemia after publication of the Randomized Aldactone Evaluation Study. $N$ Engl J Med. 2004;351:543-51.

3. Wei L, Struthers AD, Fahey T, Watson AD and Macdonald TM. Spironolactone use and renal toxicity: population based longitudinal analysis. BMJ. 2010;340:c1768.

4. Einhorn LM, Zhan M, Hsu VD, Walker LD, Moen MF, Seliger SL, Weir MR and Fink JC. The frequency of hyperkalemia and its significance in chronic kidney disease. Arch Intern Med. 2009;169:1156-62.

5. Chamsi-Pasha MA, Dupont M, Al Jaroudi WA and Tang WH. Utilization pattern of mineralocorticoid receptor antagonists in contemporary patients hospitalized with acute decompensated heart failure: a single-center experience. J Card Fail. 2014;20:229-35.

6. Rossignol P, Dobre D, McMurray JJ, Swedberg K, Krum H, van Veldhuisen DJ, Shi H, Messig M, Vincent J, Girerd N, Bakris G, Pitt B and Zannad F. Incidence, determinants, and prognostic significance of hyperkalemia and worsening renal function in patients with heart failure receiving the mineralocorticoid receptor antagonist eplerenone or placebo in addition to optimal medical therapy: results from the Eplerenone in Mild Patients Hospitalization and Survival Study in Heart Failure (EMPHASIS-HF). Circ Heart Fail. 2014;7:51-8.

7. Rossignol P, Girerd N, Bakris G, Vardeny O, Claggett B, McMurray JJ, Swedberg K, Krum H, van Veldhuisen DJ, Shi H, Spanyers S, Vincent J, Fay R, Lamiral Z, Solomon SD, Zannad F and Pitt B. Impact of eplerenone on cardiovascular outcomes in heart failure patients with hypokalaemia. Eur J Heart Fail. 2016. 8. Ponikowski P, Voors AA, Anker SD, Bueno H, Cleland JG, Coats AJ, Falk V, Gonzalez-Juanatey JR, Harjola VP, Jankowska EA, Jessup M, Linde C, Nihoyannopoulos P, Parissis JT, Pieske B, Riley JP, Rosano GM, Ruilope LM, Ruschitzka F, Rutten FH, van der Meer P and Authors/Task Force M. 2016 ESC Guidelines for the diagnosis and treatment of acute and chronic heart failure: The Task Force for the diagnosis and treatment of acute and chronic heart failure of the European Society of Cardiology (ESC)Developed with the special contribution of the Heart Failure Association (HFA) of the ESC. Eur Heart J. 2016;37:2129-200. 
9. Pitt B and Rossignol P. Potassium lowering agents: Recommendations for physician and patient
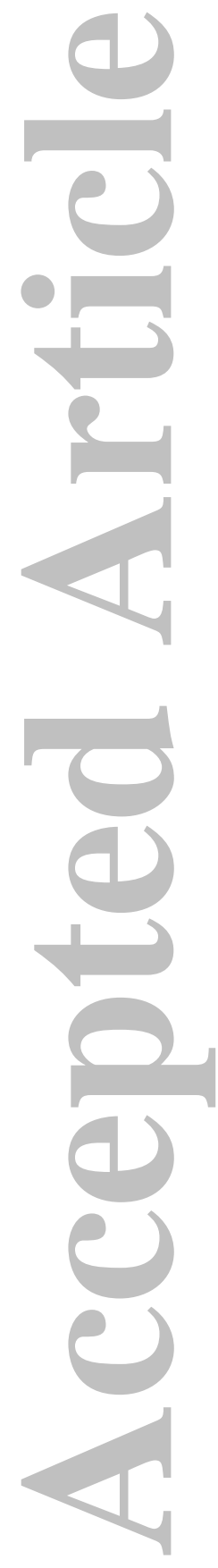